\title{
Recovery of phosphorus from sludge incineration ash
}

\author{
Mohammed Jaafar Ali Al-Atabi \\ Assist Lecturer, Collage of Engineering -Environmental Engineer Dept. AL-Mustansaryah University
}

Rec. 21 July, 2012 Accpt. 2 Aug, 2012

\begin{abstract}
The incineration of sludge is considered as one of the most common process in many landfill and municipal wastewater treatment sites. Incineration can reduce the sludge volume by eliminating the organic content and the potential energy can be utilized. The remaining materials after incineration are the nutrients and the inorganic material. Phosphorus is one of the most important nutrient that is resulting from incineration and it may be recovered by dissolving the leached incineration ash with one of concentrated acid. In this research paper the wasted of incinerated sludge ash that are resulting from municipal sludge incineration are used and then dissolved by nitric acid $\mathrm{HNO}_{3}$ with different concentration and contact time. . The results showed that the dissolving with nitric acid concentration of $30 \%$ or more than that with duration of 3 hours gives a percentage dissolving of phosphorus equal to $88.5 \%$ of the phosphorus that existing in sample. The process of phosphorus recovery from sludge incineration is very important process due to its economical benefits and to reduce the pollutants in the environment.
\end{abstract}

Keywords: Sludge incineration ash; Phosphorus recovery; Nitric Acid.

\section{Introduction}

Sustainable handling of municipal waste and sewage sludge has as an important goal to recycle resources without supply of harmful substances to humans or the environment (Adam, C. 2009). Another important goal is to avoid or reduce the amount of waste and sludge that has to be deposited on landfill. On leaching with acid it is difficult to recover phosphorus as other products than iron phosphate, which is dissolved together with the phosphorus (Balmér, P. 2003). Without removing iron from the leachate, phosphate will preferentially be recovered as iron phosphate, which has a lower solubility than for instance calcium phosphate (Balmér, P. 2004). Recovery of the phosphate as other product than iron phosphate requires that iron has to be removed from the leachate before the phosphate can be recovered. However, iron phosphate has no commercial value as raw material for the phosphate industry, and the low solubility makes it less favorable to use as fertilizer (Cordell, D., Drangerta, JO. and White, S. 2009). The global deposits of economically mineable phosphate are estimated to be 109 ton phosphorus and the total amount in the sediments is estimated to be 1015 ton phosphorus (HELCOM. 2009, Butcher et al., 1994). Many different phosphate minerals are available, but only apatite (calcium phosphate, $\mathrm{Ca} 3$ (PO4)2) is used for phosphate production (Hermann, L. 2009a, Corbridge, 1995). Since the phosphate in the sludge originate from phosphorus products produced from calcium phosphate ore, recovering the phosphate as iron phosphate will not preserve the limited calcium phosphate resources (Hermann, L. 2009b). In the proposed BioCon process ash from sludge incineration would be leached with acid and the content in the leachate separated with ion exchange technology (Petzet, S. and Cornel, P. 2009; Levlin, 2001). However in the sludge incineration plant built by the BioCon Company in Falun and Mora, the phosphate recovery process based on ion exchange has been abounded (Schmidt, E. 1998). The proposed phosphate recovery process is to leach the ash with sulphuric acid and recover the phosphate as iron phosphate (NyTeknik, 2002).

\section{Experimental Work:}

Ashes from sludge incineration were collected from AL-Rustamayh municipal waste treatment plant (Baghdad) .Leaching

\footnotetext{
Corresponding author:

Dr. Mohammed Jaafar Ali Al-Atabi

$凶$ jjafer55@yahoo.com
} 
agent used was Nitric acid supplied by (Fluka), Ether supplied by (BDH). Mineral composition of the solutions obtained by digestion of the ashes was determined by atomic absorption spectrophotometer (Shimadzu). A mass of ashes was grinded by ball mill, sieved in order to obtained $(<63 \mu \mathrm{m})$, washed by water to remove any soluble agent, dried to $105{ }^{\circ} \mathrm{C}$, washed by ether (to remove undesirable accumulated organic residual that may prevent the leaching process), dried and mixed to render the solid homogeneous. Solutions of nitric acid were prepared with different percentages $(10 \%, 20 \%, 30 \%)$, then $5 \mathrm{mg}$ of the residuals ash samples was used for each experiment, mixed with $10 \mathrm{~cm}^{3}$ with the solution of $\mathrm{HNO} 3$ in $25 \mathrm{~cm}^{3}$ Pyrex test tube and shacked in desired temperature (30, 40, 50 and 60$){ }^{\circ} \mathrm{C}$ in AAKE thermostat water bath at different contact times. Samples were settled using a centrifuge. The solution was then taken to analyses using atomic absorption spectrophotometer.

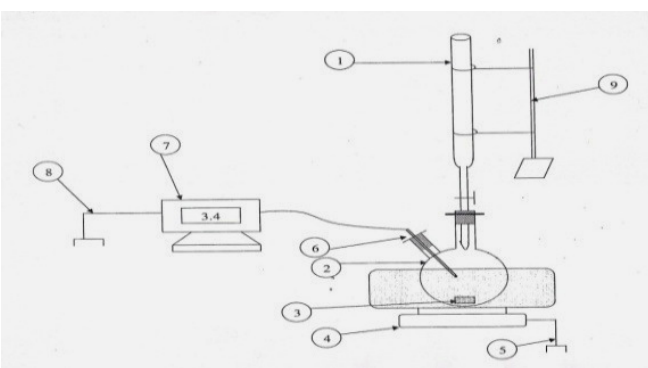

Fig. (1) Experimental rig for the experimental work

1- Calibration tube 2-Conical flax 3Magnetic stirrer 4-Water bath

5- Electrical connection 6- Thermocouple

7- Temperature indicator

\section{Results and Discussion:}

The effect of temperature and time for different nitric acid concentration is shown in figures 1,2and 3. Examining these figures indicates that the recovery of phosphorus increased with increasing time and temperature. A severe increase in phosphorus recovery was noted at the first half hour, then a more sluggish curve was obtained, this was attribute to a decline in driving force due to the consumption of the of most phosphorus in solid particles. On the other hand it was found that a small increase in temperature leads to high shift in the recovery of phosphorus, this can be explained as fallow, there are three main resistances or steps controlling the leaching process, kinetic of the process, intra particle mass transfer and mass transfer from particle to the surrounding media. If the controlling step is the intra-particle, then the effect of temperature came from its effect on effective diffusivity. If the chemical reaction step is the controlling step then the temperature due to effects the constant of reaction rate, (Schaum, C., Cornel, P., Jardin, N. 2004). The chemical step is usually much more temperature sensitive than the physical steps so the kinetic in this system is mostly the controlling step (Stark, K. 2004, Stark K. and Hultman B. 2003).

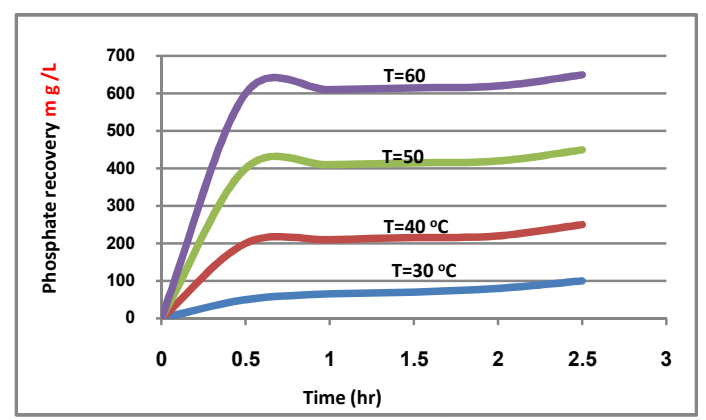

Fig. (1): Effect of time and temperature on phosphorus recovery using $10 \% \mathrm{HNO}$.

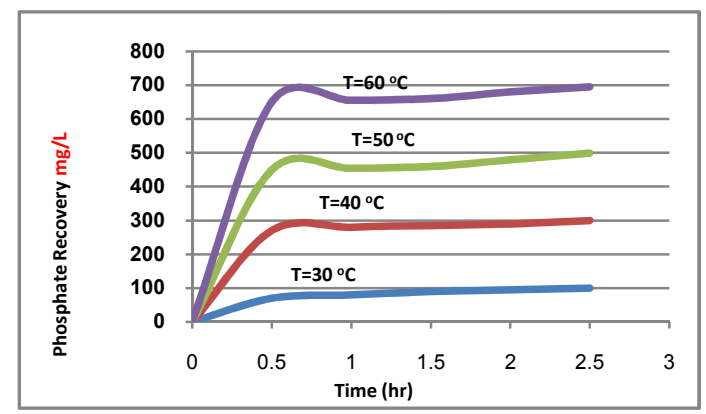

Fig. (2): Effect of time and temperature on phosphorus recovery at $20 \% \mathrm{HNO}$.

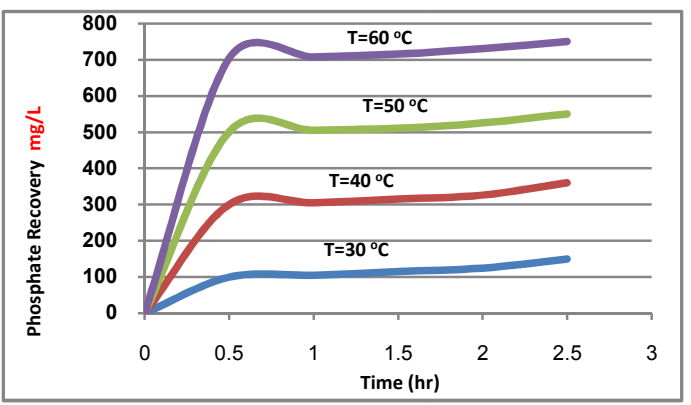

Fig. (3): Effect of time and temperature on phosphorus recovery using $30 \% \mathrm{HNO} 3$

The effect of $\mathrm{HNO} 3$ percentage on phosphorus recovery was studied by varying 
the concentration of $\mathrm{HNO} 3$ at constant temperature at $60{ }^{\circ} \mathrm{C}$ and the results is shown in figure( 4). It is clear from this figure that increasing the percentage is shifts the recovery to high values for $10 \% \mathrm{HNO}$, the recovery of phosphorus is $65 \%$ while increasing $\mathrm{HNO} 3$ to $30 \%$ and keeping the other conditions constant lead to $88.5 \%$ recovery of phosphorus.

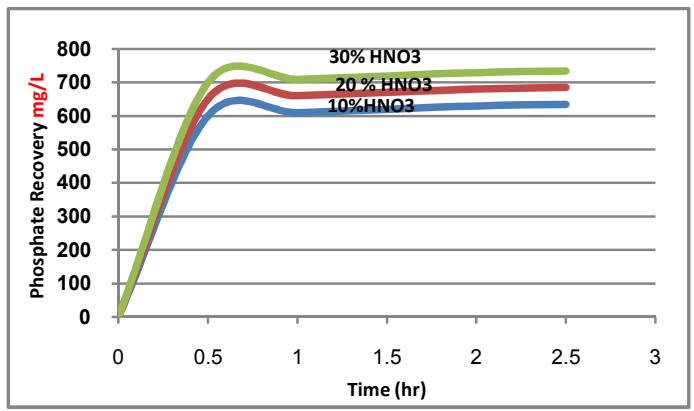

Fig. (4): Effect of time and $\mathrm{HNO} 3$ percentage on phosphorus recovery at $50{ }^{\circ} \mathrm{C}$ and leaching time $=1 \mathrm{hr}$

Figure(5) shows a comparison with the results of(Levlin ,Schmidt,2000) in which $4 \mathrm{M}$ hydrochloric acid and $70-90{ }^{\circ} \mathrm{C}$ where used, it was found that the phosphorus recovery increased with increasing temperature $(60 \%$ of phosphorus was recovered after 3 hour and $90{ }^{\circ} \mathrm{C}$ ) while in this work $88.5 \%$ of phosphorus was recovered when using $60{ }^{\circ} \mathrm{C}$ and in hour.

The leaching via $\mathrm{HNO} 3$ is preferred due to easy handling and less cost of material construction due to serious problems of corrosively o HCL .On the other hand a high recovery percent was obtained in using HNO3.

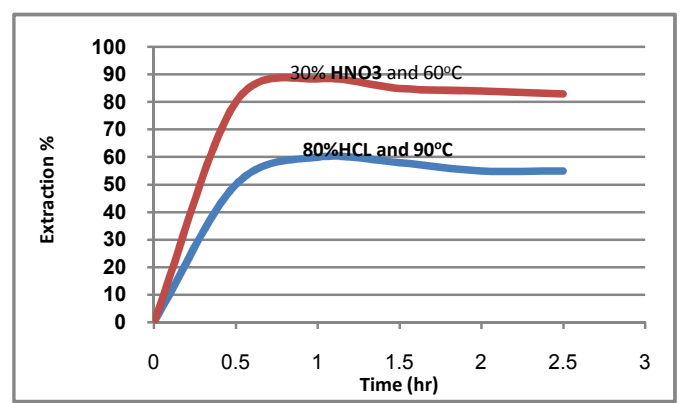

Fig. (5): Comparison with the results of (Levlin, Schmidt, 2000).

\section{Conclusion:}

The extraction of phosphorus from the sludge ash incineration was achieved using $10 \%, 20 \%$ and $30 \%$ nitric acid.

About $88.5 \%$ of phosphorus was recovered at $30 \%$ nitric acid and $60{ }^{\circ} \mathrm{C}$. The rates of extraction increase with the increase in nitric acid concentration and temperature and most $(60 \%)$ of phosphorus was recovered at the first half of an hour. This study suggested that using nitric acid is applicable to recover the phosphorus from the ashes sludge incineration of municipal treatment plant.

\section{References:}

Adam, C. (2009). Techniques for Precovery from wastewater, sewage sludge and sewage sludge ashes an overview. Presentation in BALTIC 21 Phosphorus Recycling and Good Agricultural Management Practice, September 2830, 2009. Berlin.

Balmér, P. (2003). Ref. Cornel, P. and Schaum. 2009. Phosphorus recovery from wastewater: needs, technologies and costs, Water Science and Technology, 59 (6).

Balmér, P. (2004). Phosphorus recovery an overview of potentials and possibilities, Water Science and Technology, 49 (100).

Corbridge, D.E.C. (1995) Studies in Inorganic Chemistry 20, Phosphorus, An Outline of its Chemistry, Biochemistry and Uses, 5 th ed, Elsevier Science, ISBN 0444-89307-5.

Cordell, D., Drangerta, JO. and White, S. 2009. The story of phosphorus: Global food security and food for thought. Global Environmental Change, 2.

HELCOM. (2009). Eutrophication in the Baltic Sea - An integrated thematic assessment of the effects of nutrient enrichment and eutrophication in the Baltic Sea region. Balt. Sea Environ. Proc. No. 115B.

Hermann, L. (2009). a. Recovery of phosphorus from wastewater treatment. Areview. (Rückgewinnung von Phosphor aus der Abwassereinigung. Bestandesaufnahme).

UmweltWissen Nr. 0929. Bundesamt für Umwelt (BAFU).Bern. (In German)

Hermann, L. (2009). b. recovery from sewage sludge ashes by Thermo chemical treatment. Presentation in BALTIC 21 Phosphorus Recycling 
and Good Agricultural Management Practice, September, 2009.

Hultman, B. and Levlin, E. (1997). Paper 5 Sustainable sludge handling, In: Advanced Wastewater Treatment Report No. 2, Proceedings of a Polish-Swedish seminar, KTH, Stockholm, May 30, 1997, Joint Polish -Swedish Reports, Div. of Water Resources Engineering, Royal Inst. of Tech., TRITA-AMI REPORT.

Levlin, E., Löwén, M., Schmidt, E., Hultman, B. and Mossakowska, A. (2000). Phosphorus recovery from sewage sludge incineration ash. 1 st World Water Congress of IWA, July $3-6,2000$.

NyTeknik, (2002). Tvist om bästa slamrening (Dispyt about the best sludge cleaning) Ny Teknik, 8/5 2002.

Petzet, S. and Cornel, P. (2009). Precovery from sewage sludge and sewage sludge ashes. Presentation in BALTIC 21 Phosphorus. Recycling and Good Agricultural Management Practice, September, 2009.

Schaum, C., Cornel, P., Jardin, N. (2004). Phosphorus Recovery from sewage sludge ash, Hahn, H. H., Hoffmann

Schmidt, E. (1998). Possibilities to recover phosphorus from sewage sludge before and after incineration, Diploma work, Div. of Water Resources Engineering, Royal Inst. of Tech., AVAT-EX-1998-04.

Stark, K. (2004). Phosphorus recovery from sewage sludge Experiences from European countries. Proceedings of Polish Swedish seminars, Stockholm June 68, 2004

Stark, K. and Hultman, B. (2003). Phosphorus recovery by one- or two-step technology with use of acids and bases. Proceedings of IWA specialist conference Bio solids 2003 Wastewater sludge as a resource, June 23-25, 2003, Trondheim, Norway, pp. 281-288.

\section{اعادة الفسفور من فضلات رماد الحماة المحترق}

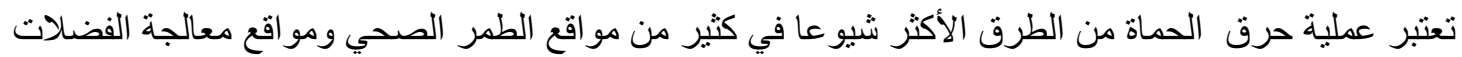

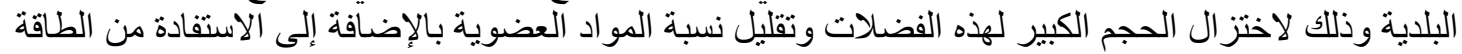

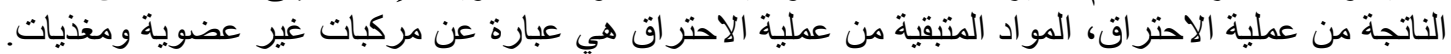

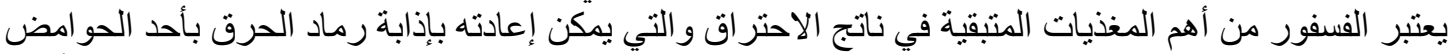

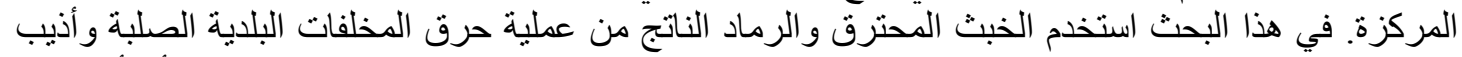

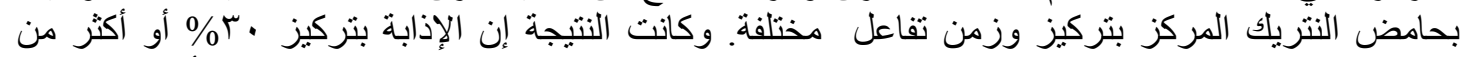

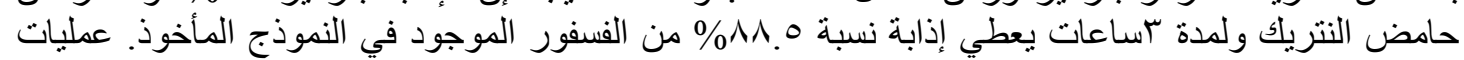

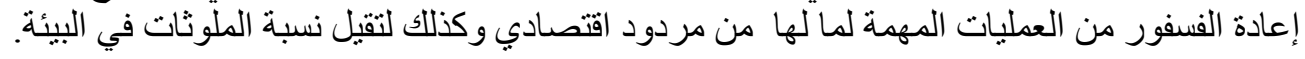

